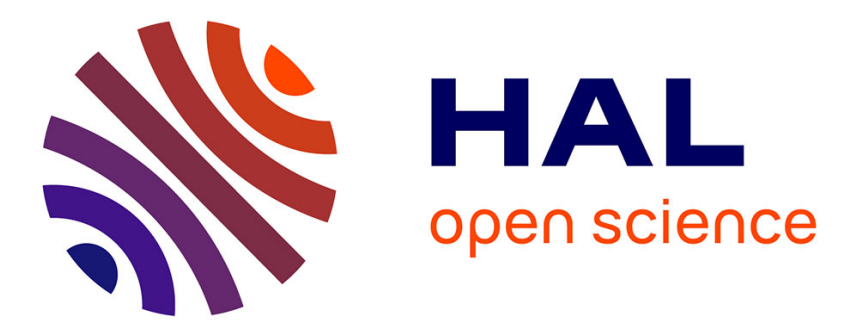

\title{
Primary School Students' Choices in Writing Opinion Essays: Using ICT Combined with Self-Regulated Strategies
}

\author{
Catarina Liane Araújo, António José Osório, Ana Martins
}

\section{To cite this version:}

Catarina Liane Araújo, António José Osório, Ana Martins. Primary School Students' Choices in Writing Opinion Essays: Using ICT Combined with Self-Regulated Strategies. 11th IFIP World Conference on Computers in Education (WCCE), Jul 2017, Dublin, Ireland. pp.323-334, 10.1007/9783-319-74310-3_34. hal-01762911

\section{HAL Id: hal-01762911 \\ https://hal.inria.fr/hal-01762911}

Submitted on 10 Apr 2018

HAL is a multi-disciplinary open access archive for the deposit and dissemination of scientific research documents, whether they are published or not. The documents may come from teaching and research institutions in France or abroad, or from public or private research centers.
L'archive ouverte pluridisciplinaire HAL, est destinée au dépôt et à la diffusion de documents scientifiques de niveau recherche, publiés ou non, émanant des établissements d'enseignement et de recherche français ou étrangers, des laboratoires publics ou privés. 


\title{
Primary School Students' Choices in Writing Opinion Essays: Using ICT combined with Self- Regulated Strategies
}

\author{
Catarina Liane Araújo [0000-0003-3930-7352], António José Osório [0000-0002-9931-1962], \\ Ana, Paula Loução Martins [0000-0002-2848-5754] \\ Education Research Centre, Institute of Education - University of Minho, Portugal \\ catarinaliane@gmail.com
}

\begin{abstract}
The process of learning how to write is a demanding, slow, and complex process. Primary school students often experience problems in writing and, therefore, teachers should provide scientifically validated strategies to empower their performance, such as Self-Regulated Strategy Development (SRSD). Reflecting on the changes in the social reality and students' personal interests, the inclusion of Information and Communication Technologies (ICT) in the educational context and practice in writing has also become exceedingly relevant. However, using ICT associated to other teaching methodologies is not always explored in the classroom. In a quasi-experimental study, 178 fourth grade students participated in an opinion essay writing intervention, during 12 weeks (90 minutes/week), using SRSD instruction model $(\mathrm{n}=89)$ and an ICT variant of SRSD called SRSD+ICT model $(n=89)$. We analyzed the impact of these two interventions through the analysis of opinion texts produced, by handwriting, for students one week before and one week after the intervention according to the elements, quality, number of words and number of linking words. Both showed positive results in the students' writing skills, although the results from the SRSD+ICT model were better. These results reinforce the pertinence and usefulness of this model in the teaching-learning process of writing that should be discussed and tested in different contexts.
\end{abstract}

Keywords: "Writing”, "Self-Regulated Strategy Development”, "Information and Communication Technology”, "Primary Education”, “Evidence Based Practice”.

\section{Introduction}

Writing is a complex, slow and demanding activity that requires knowledge, training and the mobilization of multiple processes (e.g. Hayes Model of Writing [1]). In an increasingly demanding and competitive society, we consider that early teaching of writing opinion essays is fundamental in order to enable students to possess the necessary skills and tools to clearly express their point of view on what surrounds them.

It is in primary education that teachers and students spend more time in teaching and learning the writing process and, according to curriculum goals and programs, it is expected that students will acquire important writing skills during this teaching stage. However, it is known that there are students who present problems in writing, 
which translates into the presence of inferior writing performances when compared with their peers (e. g, quality, extension) and misperceptions about their knowledge and self-efficacy in writing. Moreover, teachers also state they lack the knowledge to effect strategies necessary to deal with the difficulties these students experience.

Consequently, schools are not providing adequate answers to the level of writing $[2,3]$. Therefore, it is necessary for teachers to be familiar with effective teaching and intervention practices supported by evidence from well-conducted research studies in order to help their students succeed. Self-Regulated Strategy Development (SRSD) is an example of this, recognized as an Evidence Based Practice (EBP), which is an explicit, flexible and robust instruction model with international scientific validity, and considered highly effective in writing [2]. Despite this, further research is still needed in order for students to become competent writers [4]. It is therefore fundamental to develop more powerful and explicit interventions with students with writing problems [5].

Another of our concerns is that we need to accept that today new challenges have been placed on teachers and students in the writing process as a consequence of technological expansion in society, which has increased the diversity and complexity of writing formats and media. Consequently, this sometimes results in a disconnection between writing activities both inside and outside the classroom [6]. Therefore, being able to write properly, according to the different contexts of communication and including the use of technologies, is becoming increasingly important for the academic, social and professional development of students [4], and continues to advocate conservative pedagogical practices, ignoring the new environments and formats of written communication [7].

In this sense, we propose an adaptation of the SRSD model that integrates the selfregulated use of ICT resources and methodologies, as well as other EBP in the classroom during the teaching-learning process of writing opinion texts, calling this: the SRSD+ICT Model.

Thus, the aim of this study is to verify the impact of the SRSD + ICT model in the opinion essay writing performance of 4th grade primary school students, and which we consider to have the potentials to improve students' writing performance, even when students are writing manually, helping them to understand and execute the writing process. We will also describe the elements that contributed to the construction of the SRSD + ICT model.

\section{Background}

The results of the last 35 years of research developed around the world show that the SRSD model has a confirmed positive effect on students' performance in writing and in promoting students' self-efficacy, attitudes and motivation for writing, including students with Learning Disabilities (LD) and Writing Problems (WP), which tends to be maintained and generalized [8,9]. Nevertheless, the success of using the SRSD model with all students is not guaranteed, depending on who, with whom and how the intervention is applied. Thus, researchers in writing recognize the need for more research with the SRSD model that reflects the complexity of writing learning and student's diversity [4]. 
Nowadays, Information and Communication Technologies (ICT) are socially compelling and attractive resources for most students [10,11]. Also, ICT consist of powerful, interactive and flexible tools for the teaching and conclusion of quality writing among students, with and without LD [12]. Thus, several authors advocate for learning spaces with planned practices, which include the use of multimedia and technology, which offer interesting, diversified, authentic and purposeful writing tasks [13].

Although research in the field has recognized the potential of ICT in education, it is known that the use of technological resources alone is not a more effective determinant of learning, since its effectiveness will always depend on other aspects (relevance, resources, motivation, predisposition to use, perceptions of effectiveness) [14].

\section{The Present Study}

In this context, given that the SRSD model has a flexible nature, it allows us to combine it with other EBPs and adapt practices to the needs of teachers and students.

Before start the intervention, the students involved in this study defined goals to be achieved by the end of the intervention: the main objective of improving the writing of opinion texts and a specific objective according to the category in which they presented the lowest performance in writing quality of the following: a) theme and typology; b) information coherence and adequacy; c) structure and cohesion; d) morphology and syntax; e) vocabulary repertoire; f) spelling in the pre test. An example of a specific goal defined by a student was "writing opinion pieces with fewer errors."

\subsection{Interventions (SRSD and SRSD+ICT intervention)}

The instructions of the models were carried out in the classroom context by the same researcher, with verification of the procedures adopted by the class teachers using a context of preventive intervention [18]. We recognize that the intervention in the classroom is a limitation of the study, but this allows us to study the impact of these interventions in a less studied context and later to make it available to students in order to respond to their characteristics and needs.

After that, each group of students started the intervention SRSD or SRSD+ICT model, with the same instructor. We have applied all the principles, characteristics and stages of the SRSD model in conjunction with Revised Bloom's Taxonomy (remember, understanding, applying, analyzing, evaluating and creating) in both groups. Thus, the Revised Blooms' Taxonomy [15] allowed us to guide the teachinglearning process, in order to respect the complexity of the processes and sub processes involved and the maturation of students' cognition.

\section{SRSD model}

In the SRSD model, we followed its typical characteristics, procedures and steps. Initially, the following phases were used: 1) developed knowledge about linear writing and its contexts (e. g What do you know about writing? What type of essays 
do you know?); 2) discussion about the characteristics typically present in quality opinion essays (e.g. What is a good essay?); 3) modeling the writing of linear texts (instructor explicitly shows how students can do the self-instructions stages, selfmonitor their progress and feedback, undertake self-reinforcement with positive demonstrations or self-statements and reflect about how to use different writing strategies and techniques) and 4) memorization, through the use of mnemonics for all essays POW [8]: Pick my idea, Organize my notes, Write and say more (POW was adapted in Portuguese to PATO [10]) and the use of mnemonics Structure for opinion essays, adapted in Portuguese from TREE (Topic sentence - Head; Reasons - Trunk and Explain reasons and Ending - Members); 5) peer practices and 6) independence. The following Figure 1 (see below) shows some students' activities using SRSD model (self-statements, drawing used to plan writing and PATO mnemonic).

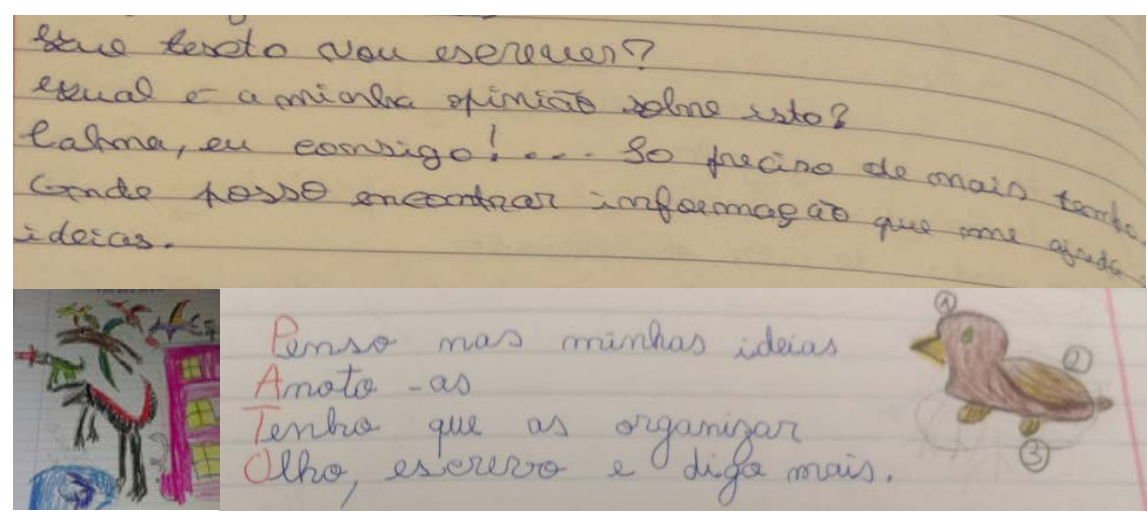

Fig 1. Representation of SRSD model and some activities in classroom

This group did not use ICT during the intervention but used a variety of materials such as searching in books or publications on school placards, which ensured the approach contained aspects similar to those used in the SRSD model. Subsequently, after this study, the students and teachers of this group had the possibility of receiving the instructions with the SRSD + ICT model.

\section{SRSD+ICT model}

In the SRSD+ICT model, we initially used the following phases: 1) development of knowledge about linear writing and its contexts; 2) discussion about the characteristics typically present in quality opinion essays; 3) modeling the writing of linear texts and 4) memorization, through the use of mnemonics for all essays (PATO) and for opinions essays (Structure). Later, we proceeded with the following phases: 5) development of knowledge about multimodal writing; 6) discussion about the characteristics and contexts of multimodal writing, including the different writing formats (e.g. auditory, visual); 7) modeling the multimodal writing. In these phases, we also included the use of ICT tools in the process according to these steps: a) the presentation of tools and some of the potentialities for writing; b) discussion with students and c) modeling the use of tools in text production. After that, we followed on with peer practices (8), where all students explored the use of research-based ICT 
tools (e. g. word processor, spell checker, mental maps, speech synthesizers and others) and reflected on how and when ICT could support their learning process of writing. In this way, all the students experimented with different tools and had the possibility to choose whether or not to use a certain tool during the writing process. Furthermore the students analyzed individual or group potential and identified the constraints of specific use of ICT in the writing process. The Figure 2 (see below) shows the explicit approach of areas that contributed to the SRSD + ICT model for the teaching-learning process of writing opinion essays. The following Figure 3 (see below) shows an example of mental maps created by students using SRSD+ICT model.

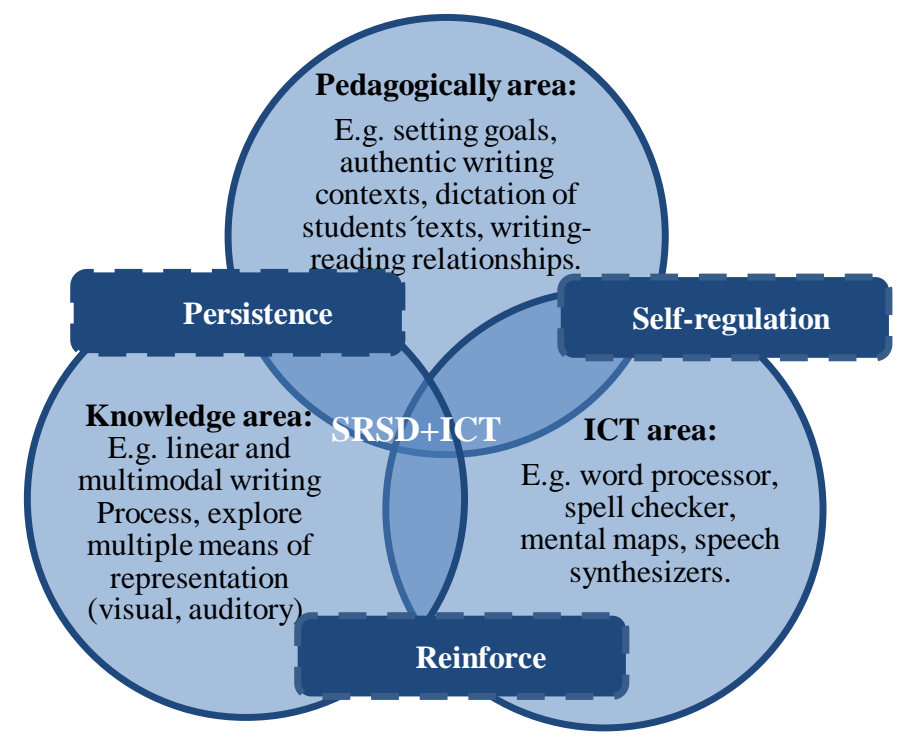

Fig. 2. Representation of explicit approach of areas that contributed to the SRSD + ICT model and same activities in classroom.

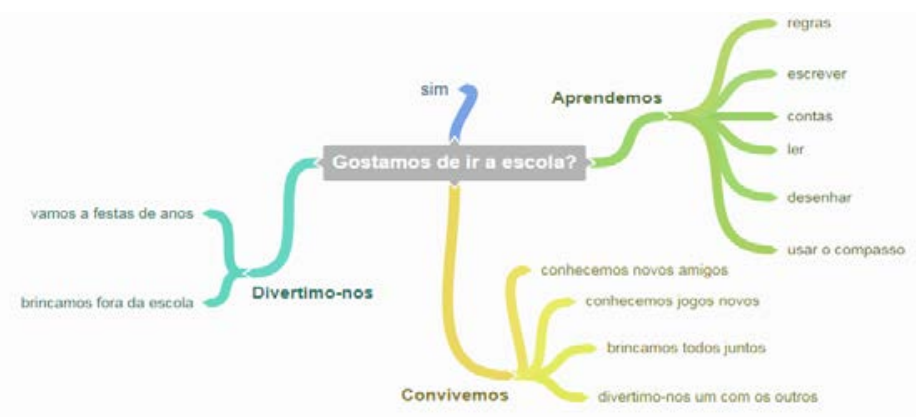

Fig. 3. Mental maps created by students during the opinion essay writing process using SRSD+ICT model, in Coogle 
Finally, the students' independence in writing was stimulated and, together with the teacher, each student decided if and when to use ICT for their writing process, as well as using other forms of writing to help their writing process (e. g. auditory, visual). It should also be noted that the ICT resources of the students' families, including computers, tablets and mobile phones, were used and that the introduction of these technologies in the classroom for writing promoted more active and proactive dynamics among students.

\section{Methodology}

This study used a quasi-experimental methodology to analyze the impact of two different interventions, SRSD+ICT and SRSD, in 178, 4th grade student's performance of writing opinion essays, divided equally into two groups, after 12 weeks of instruction (90 minutes/week) in Braga, Portugal. Variables such as gender, presence of socioeconomic support to families, presence of writing problems and presence of special educational needs were controlled. Also, the writing practices of students in the classroom, collected through observations, interviews and a questionnaire for teachers, were taken into account for the interpretation of the results. We also evaluated the fidelity and social validity of the interventions with students and teachers.

\subsection{Participants}

The initial sample consisted of 205 students attending the 4th grade of public school education in Braga, Portugal. However, 23 students were transferred, missed the pretest or corresponded to students in Special Education and Specific Curriculum. Also, another 10 students who did not perform at least two-thirds of the intervention were excluded from the sample. Thus, the final sample included 174, 4th grade students, and this sample was divided equally into two groups (87 students in SRSD group and 87 students in SRSD+ICT group). All the participants were taught by the same teacher during the interventions. The mean age was 9.5 years $(\mathrm{SD}=.578$, ranged from 9-12) and more than half of the students were males ( $n=111,54.1 \%$ ). Application protocols validated by full professors and students were used. 42 students with writing problems (20.5\%) were included in the sample however students supported in special education and specific curriculums were excluded from the sample, leaving the rest who were integrated in the sample (3.4\%).

\subsection{Writing measures and procedures}

Assessments tasks procedures. Students were asked to write an opinion essay one week before the start of the instructions (pretest) and one week after the instructions (posttest). For each text, a topic question about familiar subjects that guided the writing of the text was given (e.g. What is your favorite season of the year?; What is your favorite game?) and students then had 45 minutes to write their opinion essays.

Evaluation procedures for score performance in writing opinion essay. After collecting pre and posttest students' opinion essays samples their performance in writing opinion essays was evaluated according to the structure, quality, number of 
words and number of linking words of written opinion essays and using the following instruments described in table 1 .

Table 1. Instruments used for scoring performance

\begin{tabular}{|l|l|}
\hline $\begin{array}{l}\text { Variables } \\
\text { measures }\end{array}$ & Instruments and Scores \\
\hline Elements & $\begin{array}{l}\text { Instrument used: Elements score scale of opinion essays from Scardamalia and } \\
\text { Bereiter [16]. One point per presence of: 1) topic sentence; 2) reasons; 3) } \\
\text { arguments; 4) examples; 5) final sentence. The final structure score is a result of } \\
\text { the sum of the points obtained. Repeated ideas are only counted once. }\end{array}$ \\
\hline Quality & $\begin{array}{l}\text { Instrument used: Portuguese National Scale for the assessment of the Writing } \\
\text { performance of 4th grade students [17]. Assign a score between 1(unsatisfactory) } \\
\text { and 5 points (Excellent) in each next dimensions: a) theme and typology; b) } \\
\text { information coherence and adequacy; c) structure and cohesion; d) morphology } \\
\text { and syntax; e) vocabulary repertoire; f) spelling. The quality scores result of the } \\
\text { average of the evaluated in each dimension previous presented. }\end{array}$ \\
\hline $\begin{array}{l}\text { Number } \\
\text { of Words }\end{array}$ & $\begin{array}{l}\text { The number of words was recorded on the computer using Microsoft Office and } \\
\text { verified by the authors (e.g. 1 meaning 1 words writing). }\end{array}$ \\
\hline $\begin{array}{l}\text { Number } \\
\text { of } \\
\text { Linking } \\
\text { Words }\end{array}$ & $\begin{array}{l}\text { Linking words are words that serve to connect ideas in a sentence that can help } \\
\text { writer to addicting (e.g. also), sequencing (e.g. first) illustrating (e. g. for } \\
\text { example), comparing (e.g. similarly), qualifying (e.g. except), contrasting (e.g. } \\
\text { alternatively), summary (e.g. in short), emphasizing (e.g. above all) or establish } \\
\text { relations of cause and effect (e. g. because) in the essay. The number of linking } \\
\text { words was counted manually. For each linking word different is assigned by 1. }\end{array}$ \\
\hline
\end{tabular}

Analysis procedures. For data collection, analyses of descriptive statistics were performed through frequency measurements, central (mean) and dispersion (standard deviation), extreme (maximum and minimum) and quartile patterns using SPSS. Inferential statistics were used through the Student's t-Test for the comparison of means between independent sample and also analysis of variance for repeated measurements for determining and analyzing significant differences between elements, quality, number of words and number of linking words on the intervention (SRSD or SRSD+ICT).

\section{Results and discussion}

As expected, according to the results obtained in previous studies, the positive results of the use of the SRSD model in writing performance [e.g. 4, 19, 20]. As for the SRSD + ICT model, given the combination of several EBP, self-regulation processes and models of educational technologies with positive evidence in the orientation of the learning process, we expect that it can contribute to the improvement of the writing performance of these students. Thus, the results of the writing performance of students' opinion essays are presented below in Table 2: 
Table 2. Students' Opinion Essay Writing Performance between pretest and posttest in each intervention according to the elements of writing, quality of writing, number of words and number of Linking Words.

\begin{tabular}{|c|c|c|c|}
\hline \multirow[b]{3}{*}{ Writing style } & \multirow[b]{3}{*}{ Time } & \multicolumn{2}{|c|}{ Interventions group } \\
\hline & & $\overline{\text { SRSD }}$ & SRSD+ICT \\
\hline & & $\begin{array}{l}\mathrm{M}(\mathrm{SD}) \\
(\mathrm{n}=87)\end{array}$ & $\begin{array}{l}\text { M (SD) } \\
(n=87)\end{array}$ \\
\hline \multicolumn{4}{|l|}{ Opinion Essay } \\
\hline \multirow{2}{*}{ Elements } & Pre test & $3.51(1.50)$ & $3.53(1.23)$ \\
\hline & Post test & $5.87(2.23)$ & $6.71(1.86)$ \\
\hline \multirow[t]{2}{*}{ Quality } & Pre test & $3.02(0.89)$ & $2.96(0.81)$ \\
\hline & Post test & $4.03(0.63)$ & $4.34(0.55)$ \\
\hline \multirow[t]{2}{*}{ Number of words } & Pre test & $93.93(31.51)$ & 108.95 (33.38) \\
\hline & Post test & 90.19 (39.64) & $114.14(33.79)$ \\
\hline \multirow[t]{2}{*}{ Number of Linking Words } & Pre test & $2.64(1.12)$ & $2.97(1.07)$ \\
\hline & Post test & $4.22(2.26)$ & $4.86(1.78)$ \\
\hline
\end{tabular}

The results in Table 2 demonstrate that those students in the SRSD group presented a minor performance before the intervention in writing elements (with an average of at least three elements between topic sentences, reasons, contra reasons, examples or final sentence), number of words and number of linking words (less variety and quantity) than students in the SRSD+ICT group.

In contrast, the quality is lower than with students in the SRSD+ICT group. After the interventions, we observed significant improvements in elements, quality and number of linking words of opinion essays in both groups. The opinion essays were more structured (with the basic structure of this gender), were of better quality (Students progressed from unsatisfactory assessments to very good assessments) and were also more diversified using a greater number of linking words which allowed their writing to become more perceptible to readers, and helped in the organization and presentation of ideas and messages in the text to both the writer and the reader.

Regarding the number of words, used in the essays, these groups had opposite behaviours. In the SRSD group, there was an increase in the number of words while in the SRSD +ICT, there was a decrease, although both groups wrote better after their interventions. Therefore, we believe that the SRSD group extended their ideas more, while the SRSD +ICT group was more objective in their writing. These results are contrary to what was expected, since some investigations ([e. g. 14]) have shown an increase in the length of texts produced by students after intervention with this model. In this study, it was also possible to verify an improvement in the quality and structure of the texts produced by the students after the intervention, even with shorter texts. Possibly, these results are due to the fact that a guideline for the minimum number of words was used and students understood the essential elements of the text, thus reducing redundant or ancillary information, which brought the number of words written by the students closer. In contrast, students from the SRSD + ICT group, who benefited from the SRSD + ICT intervention, wrote longer texts after the intervention with a higher quality and structure, which seems to indicate the positive effects of this 
intervention for the development of the ideas produced in the text, translated in the extension of the same. From the above, it seems that the use of the SRSD + ICT model provided the students with the skills and knowledge that enabled them to improve the quality, structure and extension of texts produced. In any case, it should be noted that the results presented could be different with another group of students, and it is therefore important to develop further studies that use the SRSD + ICT model in other contexts in order to verify if the benefits evidenced at the extension level of the texts are retained or, if the results are different.

Analyzing the results obtained, according to the analysis of variance for repeated measurements, it can be verified that the variables of writing performance present a highly significant value $(p=0.00)$ in the results of the groups and in the explanation of the variance of the same, in the interception between the effect of the writing performance variables with the group $(p=0.00)$ or between the effect of the writing performance variables with the moment $(p=0.00)$. It should also be noted that the moments present a significant effect $(p \leq 05)$ on the total variance of the results. Analyzing the result obtained in the Mauchaly's sphericity test it was verified, as expected, that the sphericity assumption is not met with the performance variables $(p=0.00)$ and between the performance variables in the moment writing $(p=0.00)$, so that the values corrected through the Greenhouse-Geisser were also analyzed, being the variables $(p=.335)$ and the variables $\mathrm{x}$ moment $(p=336)$. Also, the differences found were attributed to the necessarily reduced size of this quasi-experimental design.

The results obtained in the simple linear model of repeated measures (2x2) between the SRSD + ICT and SRSD groups and the two moments of evaluation (pretest and post-test) in the study variables (writing performance variables: structure, quality, extension and connectors) by analyzing the tests of inter-subject contrasts.

It was possible to verify, through the test of effects between subjects, that there is a differentiated effect of the intervention type (SRSD + ICT intervention and SRSD) presents a highly significant value $(F=20.594, p=.000)$, which is maintained by interception between the group $\mathrm{x}$ moment $\mathrm{x}$ performance variables in writing $(F=2575,595, p=.000)$. Thus, the results show that SRSD and SRDS+ICT interventions contributed to the improvement of these 4th grade students' writing performance of opinion essays, specifically in the elements of opinion essay, quality of writing and the use of linking words which was what we had expected.

The fact that the SRSD+ICT model obtained even more positive results than those previously observed with the SRSD model as an evidence-based practice, underlines the importance of discussing how ICT can contribute to supporting the learning of writing and the analyses of how the use of the SRSD model with ICT can be positive, reiterating the importance of the transversal use of the self-regulation process to the different learning approaches. The results also reinforce the positive effects of ICT in the writing process of students already previously evidenced by other authors and in other research contexts (e.g. [20, 21, 22]). Therefore, this highlights the role of this model with respect to the individual needs of students where all are included. It also reinforces the importance of integrating the use of ICT in a self-regulated way in students' writing skills $[23,24]$ and could be explained, given the set of authors who defend its benefits, by the social and cultural changes in the use of ICTs and the fascination of children with these tools. It was also verified that there existed a greater 
dispersion in the results obtained by the students, which proves that not all students react in the same way to the use of ICT in the SRSD model, aspects previously mentioned by Tavares and Barbeiro [23].

In that way, the reflexive and critical processes were privileged in the writing process by students and teachers. For example, with regards to the word processor, some students had already used it and considered it a positive tool in the organization of texts, while other students considered writing on the keyboard a waste of time because they were not used to this form of writing. Thus, the use of the SRSD + ICT model during the teaching-learning process seems to demonstrate positive effects on students' writing performance, and helps students to understand and deconstruct the writing process, even when they write without using ICT.

\section{Conclusions and Implications}

The SRSD + ICT and SRSD interventions also demonstrated an improvement in the results regarding the structure, quality and number of argumentative connectors of the text. However, the SRSD + ICT intervention had a more positive effect on these variables since there were initially no statistically significant differences between the SRSD + ICT and SRSD groups regarding the performance in the structure, quality and number of connectors used in the opinion text. However, after the interventions, the existence of statistically significant differences between these groups was observed. Thus, the fact that the SRSD + ICT model obtained even more positive results than those previously observed with the SRSD model, as an evidence-based practice, underlines the importance of discussing how ICT can contribute to supporting the learning of writing and analyzes how the use of the SRSD model with ICT can be positive, reiterating the importance of the use of self-regulation processes transversal to different learning aspects. It highlights the role of this model in respect to the individual needs of students, where all are included.

In syntheses, both interventions showed positive results in the students' writing although the SRSD+ICT model was better. These results highlight the importance of the use of ICT in a self-regulated and associated SRSD model in order to understand the writing process of opinion essays and also, reinforce the pertinence and usefulness of this model in the teaching-learning process of writing that should be discussed and tested in different contexts.

Acknowledgments. The authors are greatly appreciative of the grants and support received in relation to the work presented in this paper, which was carried out at the Educational Research Centre, University of Minho, and financed by the Technology and Science Foundation (FCT), Portugal, by way of a PhD Grant SFRH/BD/86175/2012 that Araújo, C. L. received. We would also like to thank all the students, teachers, parents and school directors who participated in this research and also to all the researchers who shared their knowledge and help with this team to design and implement the SRSD+ICT interventions. 


\section{References}

1. Hayes, J. R. Evidence from language bursts, revision, and transcription for translation and its relation to other writing processes. In M. Fayol, D. Alamargot \& V. W. Berninger (Eds.), Translation of thought to written text while composing (pp. 15-25). Nova Iorque: Psychology Press (2012).

2. Harris, K. R., \& Graham, S. (2016). Self-Regulated Strategy Development in Writing: Policy Implications of an Evidence-Based Practice. Policy Insights from the Behavioral and Brain Sciences, 3(1), 77-84. doi:10.1177/2372732215624216.

3. McKeown, D., Brindle, M., Harris, K. R., Graham, S., Collins, A. A. \& Brown, M. Illuminating growth and struggles using mixed methods: Practice-based professional development and coaching for differentiating SRSD instruction in writing. Reading \& Writing, 29, 1105-1140 (2016). DOI: 10.1007/s11145-016-9627-y.

4. Harris, K. R. \& Graham, S. "An adjective is a word hanging down from a noun": Learning to write and students with learning disabilities. Annals of Dyslexia, 63(1), 65-79 (2013). DOI: 10.1007/s11881-011-0057-x.

5. Graham, S. \& Harris, K. R. Designing an effective writing program. In S. Graham, C. MacArthur \& J. Fitzgerald (Eds.), Best practices in writing instruction (pp. 3-25). New York: Guilford (2013).

6. Vue, G., Hall, T. E., Robinson, K., Ganley, P., Elizalde, E. \& Graham, S. Informing Understanding of Young Students' Writing Challenges and Opportunities: Insights from the Development of a Digital Writing Tool That Supports Students With Learning Disabilities. Learning Disability Quarterly, 39(2), 83-94 (2015). DOI: 10.1177/0731948715604571.

7. MacArthur, C. A. Reflections on Research on Writing and Technology for Struggling Writers. Learning Disabilities Research \& Practice, 24(2), 93-103 (2009).

8. Graham, S. \& Harris, K. R. Writing better: Effective strategies for teaching students with learning difficulties. Baltimore: Paul H. Brookes (2005).

9. Graham, S. \& Harris, K. R. Almost 30 Years of Writing Research: Making Sense of It All with "The Wrath of Khan". Learning Disabilities Research \& Practice, 24(2), 58-68 (2009).

10. Araújo (2011).Dificuldades de Aprendizagem Específicas: Um estudo Quantitativo sobre o uso de Estratégias de Autorregulação numa Turma Inclusiva. Dissertação de Mestrado em Educação Especial na área de Especialização em Dificuldades de Aprendizagem Específicas, Universidade do Minho, Braga, Portugal. Accessed on http://hdl.handle.net/1822/19536, last accessed in 2017/01/31.

11. Cope, B. \& Kalantzis, M. Multiliteracies: Literacy learning and the design of social futures. Melbourne: Macmillan (2000).

12. Kress, G. Literacy in the new media age. Londres: Routledge (2003).

13. Beach, R. \& Friedrich, T. Response to writing. In C. MacArthur, S. Graham \& J. Fritzgerald (Eds.), Handbook of writing research (pp. 248-262). Nova York: Guildford Press (2006).

14. Kellogg, R. T. Training writing skills: A cognitive developmental perspective. Journal of Writing Research, 1 (1), 1-26 (2008). DOI: 10.17239/jowr-2008.01.01.1

15. MacArthur, C. A., Schwartz, S. S. \& Graham, S. A model for writing instruction: Integrating word processing and strategy instruction into a process approach to writing. Learning Disabilities Research \& Practice, 6, 230-236 (1991). 
16. Bereiter, C. \& Scardamalia, M. From Convertation to Composition: The Role of Instruction in a Developmental Process. Advances in instructional psychology, 2, 1-64 (1982).

17. Portuguese National Scale for the assessment of the Writing performance of 4th grade students.http://bi.iave.pt/exames/download/PF-Port41-F1-2015-CC.pdf?id=6105, last accessed in 2017/01/31.

18. Fuchs, D., Fuchs, L. \& Vaughn, S. Response to intervention: A framework for reading educators. Newark: International Reading Association (2008).

19. Graham, S. \& Harris, K. R. Students with Learning Disabilities and the Process of Writing: A Meta-Analysis of SRSD Studies. In H. L. Swanson, K. R. Harris \& S. Graham (Eds.), Handbook of learning disabilities (pp. 323-344). New York: Guilford Press (2003).

20. Festas, I., Oliveira, A. L., Rebelo, J. A., Damiao, M. H., Harris, K. \& Graham, S. Professional development in self-regulated strategy development: Effects on the writing performance of eighth grade Portuguese students. Contemporary Educational Psychology, 40, 17-27 (2015). DOI: http://dx.doi.org/10.1016/j.cedpsych.2014.05.004.

21. Englert, C. S., Zhao, Y., Dunsmore, K., Callings, N. Y. \& Wolbers, K. Scaffolding the writing of students with disabilities through procedural facilitation: Using an internet based technology to improve performance. Learning Disability Quarterly, 30(1), 9-29 (2007).

22. Jonassen, D. H. Computadores, Ferramentas Cognitivas. Desenvolver o pensamento crítico nas escolas. Porto: Porto Editora (2007).

23. Tavares, C. F. \& Barbeiro, L. F. As Implicações das TIC no Ensino da Língua. Lisboa: Ministério da Educação: Direcção-Geral de Inovação e de Desenvolvimento Curricular (2011).

24. Graham, S., McKeown, D., Kiuhara, S. \& Harris, K. R. "Meta-analysis of writing instruction for students in elementary grades": Correction to Graham et al. (2012). Journal of Educational Psychology, 104(4), 896 (2012). DOI: 10.1037/a0029939. 